DOI: $10.2478 /$ rjp-2019-0006

Rom J Psychoanal 2019, 12(1):81-99

Rom J Psychoanal

\title{
IS THERE A FEMININE NARCISSISM?
}

Radu $\mathrm{Clit}^{8}$

Abstract: Freud did not describe a feminine narcissism, but pointed out the importance of this structure in women, as well as that of masculine identifications. This theme is sought after by a writer, Herta Müller, in six of her novels. She uses the first person and has both male and female protagonists, whom she should, in principle, identify with. All her characters are confronted with narcissistic anxiety (Green), in a totalitarian social context. Narcissistic anxiety is close to the neurotic anxiety, whose forms are, according to Green, the penetration anxiety in women, and castration anxiety in men. At the narcissistic level, Green proposes the intrusion anxiety, in the feminine register, and separation anxiety, in the masculine register. In Herta Müller's prose, male characters are weak, but rarely overcome with emotions, whilst female characters harbour strong feelings in their bodies. The man would be in a better position to project his anxiety towards the outside of the body, while the woman would feel it more on the inside. The situation would allow the hypothesis of feminine narcissism.

\footnotetext{
${ }^{8}$ French Society of Group Psycho-Analytic Psychotherapy; radu_clit@yahoo.fr
} 
Keywords: castration anxiety, identification, intrusion anxiety, narcissism, penetration anxiety, separation anxiety.

\section{Introduction}

The psychic apparatus generally refers to the internal structures allowing individual functioning. Only a few of them can be observed from outside. Also, the gender differences are not very important, especially regarding narcissism. But it seems Freud offered a more complex vision on this topic. So, it should be possible to propose the hypothesis of a feminine narcissism.

In On Narcissism: An Introduction, Freud shows that he has observed the choice of object among perverts and homosexuals and has found that they seek themselves as objects of love. This would have allowed 'the hypothesis of narcissism'. Then he remarks: "We say that a human being has originally two sexual objects - himself and the woman who nurses him - and in doing so we are postulating a primary narcissism in everyone, which may in some cases manifest itself in a dominating fashion in his object-choice." (Freud, 1914, p. 88) This shows the contradictory nature of narcissism: a libidinal cathexis of oneself, it is expressed in the choice of object, so the choice of the other. Freud then develops the idea of the existence of a category of women that give the impression of loving themselves more than they love men: "Strictly speaking, it is only themselves that such women love with an intensity comparable to that of man's love for them. Nor does their need lie in the direction of loving, but of being loved; and the man who fulfils this condition is the one who find favour with them. The importance of this type of woman for the erotic life of mankind is to be rated very high. 
Such women have the greatest fascination for men, not only for aesthetic reasons, but also because of a combination of interesting psychological factors." (Ibid., p. 89)

Is this a typical feminine narcissism? Apparently not, because Freud compares the charm of such women with the charm of the child, or that of certain animals, to add the charm of the criminal and the humourist. But unlike all these cases, he conceives that the love of these women can find the child they will give birth to as an object. Finally, this will allow them to be less focused on themselves. Freud evokes another possible situation: "There are other women, again, who do not have to wait for a child in order to take the step in development from (secondary) narcissism to object-love. Before puberty they feel masculine and develop some way along masculine lines; after this trend has been cut short on their reaching female maturity, they still retain the capacity of longing for a masculine ideal - an ideal which in fact a survival of the boyish nature that they themselves once possessed." (Ibid., p. 90)

It appears that these women have masculine identifications, unlike the first ones who do not have any. Would the absence of masculine identifications be characteristic of feminine narcissism? Without saying it so explicitly, Freud suggests that the narcissistic woman would demonstrate an inability to identify with the man. It is interesting to explore the masculine identifications of a woman. This issue would be clearer in a female writer, because through her characters, the ease or difficulty of identification seems more accessible to observation. 


\section{Herta Müller and masculine identifications}

The chosen writer is Herta Müller, Nobel Prize winner for Literature in 2009 , who notably portrayed daily life under the communist regime in Romania. In most of her novels translated into English, the protagonists use the first person, a sign of an important identification of the author with the characters. There are six novels, and only two of them feature a male protagonist.

The first, The Passport (1989), describes the tribulations experienced by the head of a family to obtain passports allowing them to emigrate to the Federal Republic of Germany, during the communist era. This man, Windisch, is the miller of the German village where the action takes place. An important detail, because in German, the surname of the writer, 'müller' has precisely the meaning of miller. In addition, she was born and lived until adolescence in a Germanic village in Romania. In the novel, Windisch has a girl whose age would be around twenty. At the time of the publication of this book, in 1986, the writer was at least ten years older, raising the question of whether the protagonist of the novel could be a stand-in for her father. A biographical detail shows that in fact, Herta Müller began writing just after the death of her father (Clit, 2018). It would be possible to say that the character Windisch is a kind of masculine double, but also a father equivalent, concretizing his surname. In the novel, the man missed a necessary step to obtain passports - he tries to bribe the responsible authorities with flour, at a time of food shortages. Finally, it is his daughter's sexual attractiveness which is exchanged for passports, hence the idea of a man being like a pheasant word present in the original German title, which could be translated as The Man is a Big Pheasant on Earth, meaning someone naive, at least in 
Romanian culture. He believed in the promise that his flour could do the trick. It should also be noted that Herta Müller did not face this difficulty personally. Harassed by the secret political police before and after the publication of her first book, the collection of short stories Nadirs, she was compelled, on the contrary, to emigrate. There remains a certain distance between the existence of the writer and her character. Moreover, it implicitly shows that the man risks having to accept an unsatisfactory self-image, whereas, by her sexual attraction, the young woman would be more effective in this particular social context. Therefore, while describing this character in a relevant way, Herta Müller shows that her feminine identification remains more important.

The situation is quite different in the second novel taken into consideration, The Hunger Angel (2013). It is the novel that would have contributed the most to her being awarded the Nobel Prize and describes life in a Soviet labour camp. The choice of this theme is further removed from the writer's real life. The deportation to labour camps in the USSR concerned the German communities of all countries that fought against Stalin during World War II, but before the birth of the writer. In her family, it was her mother who spent five years in a camp, but without telling her about this terrible adventure. Herta Müller had found another writer, Oskar Pastior, also a German from Romania, who was in such a camp as well, and who was interested in writing a common portrayal of this experience. Pastior was actually a poet and closer to the generation of Herta Müller's parents. Actually, the collaboration was only partial, because of Pastior's death before the end of the work. The protagonist of the novel, the young Leopold Auberg, has a profile quite similar to that of Pastior. Herta Müller writes in his name. This main character has to 
deal with his homosexuality, like Pastior himself. Would this fact have facilitated collaboration? In any case, the writer has shown in her essays (Clit, op.cit.) that, for her, her mother's deportation was that which remained as a mystery to understand. Thus, Pastior, a writer like herself, would have allowed Herta Müller to better understand and identify with her own mother. Her first name, Herta, was the name of the mother's best friend, who died at the camp. There is all the burden of an unspoken intergenerational message, which made this collaboration necessary with a man who, by his profession and origins, was close to the writer. Perhaps Pastior's homosexuality was in contrast to the virile profile of the writer's father, who was a volunteer in the Waffen SS, like many men from German communities outside the Third Reich. The Germans' deportations were a form of punishment for their participation in the war against the Soviet Union. But the writer seems closer to her mother and this poet friend.

What about the writer's identifications? Apparently, through this homosexual man, she improves her relationship with her mother and her traumatic past. As in the previous novel, the man in question seems to play a secondary role in the writer's internal universe. Moreover, in The Passport the protagonist, Windisch's wife, was also suggested to have been in a camp in the USSR where she survived by sleeping with men who could facilitate her existence. Her daughter had also learnt to - in order to help her parents - sleep with men able to help her progress in life. Thus there is a sort of duality, men are either violent or with a negative image, like the writer's father, or weak beings, 'pheasants' or homosexuals who need the support of women, capable of suffering and caring for others. These two images make it possible to propose two 
models of identification that could lead to a distinction between feminine narcissism on one side, and masculine narcissism on the other. In any case, able to identify with men, the writer preserves her feminine image. We must also take into account the particular social context of the two mentioned novels. Their common element would be the endangerment of the existence of the individual. Sociological analysis has shown that it is the totalitarian regime which has terror as a principle of government (Clit, 2001).

\section{The social context}

What remains implicit in Herta Müller's prose is the anxiety with which her characters are confronted, for different reasons. For Windisch, the protagonist of The Passport, the problem seems to be the self-image. The writer's style supposes the practice of abstaining from offering sufficient contextualization. The reasons behind the decision of many people in the same village to emigrate to Germany is not very explicit. In fact, these are German communities that existed since the AustroHungarian Empire, and apparently did not consider emigrating before the communist regime. The support of Hitler's Germany led to punitive measures against them, but the possibility of emigration was the result of a contract with the Federal Republic of Germany from the 1970s. It involved a financial compensation paid to the Romanian communist regime, in a time when obtaining a passport was very difficult for anyone. The choice of Windisch and his family was rather imposed by the totalitarian regime in place. The local authorities tried to take advantage of this right to emigration, which was still difficult for German ethnic groups. What is exposed is Windisch's identity conflict, which suffers from his lack of efficiency in dealing with the authorities. 
Specifically, on the scale of the village, the policeman (in the language of the regime, the 'militia man') and the priest had imposed, to their personal gain, a sort of right to obtain sexual profit from each family having applied for passports. Windisch is extremely hurt by this requirement, but he understands that this is the price to pay for emigration. His frustration is also sexual, because his wife, following a uterine operation, does not sleep with him anymore. Some moments of depersonalization are well described, as well as the use of alcohol to deny this suffering or injury - that to which Windisch would be confronted is a form of anxiety of a narcissistic nature, remaining confined in his psychic space.

It would be easier to find this type of anxiety in the protagonist of The Hunger Angel. Beginning his sex life with men before deportation, he feels rather relieved by the departure to the USSR. He understands quite quickly that the existence there is very different from what he had known. This fact even protects him from the homosexual identity - he notices that death ravages the camp. A first inmate falls into the thatch pit and the authorities forbid her comrades any action supposed to save her life. Hunger is also an almost constant need, and becomes personified by the metaphor 'hunger angel'. The climate in the camp is an explicit form of terror, typical of totalitarian regimes - death and hunger, two fundamental dangers to human existence that were present all the time. The protagonist is described as trying to cling to life, unlike other inmates who let themselves die. Leo is involved in physical work, even if the living conditions are terrible. The food is extremely insufficient, the clothes often more bulky than protecting from the winter cold. The very fact of having emotions and feelings appears as a luxury. Relations with camp authorities are difficult. First, they speak Russian, then they put the 
prisoners in a position of overwhelming inferiority. Thus, the self-image is diminished to a manimum, in a context where losing life becomes extremely simple! What about narcissism? It is almost annihilated, reduced to self-preservation in Leo's case, unlike the other character, Windisch. But one could postulate the presence of narcissistic anxiety in both cases.

\section{Narcissistic anxiety}

Narcissistic anxiety has been described by Green, among others. He shows that the ego is the instance that triggers anxiety when object investments pose a threat to it (Green, 148). But the question of whether the self triggers anxiety in relation to its own cathexis is not asked by Freud. In evoking the pain, Green compares it to a wound, a haemorrhage flowing through the laceration of injured narcissism. "This means that narcissistic unity is compromised." (Ibid.) The ego itself would be damaged as a functional entity. The ego would come from the attempt to replace the object. The image of the object is copied thanks to the capacity to fantasize, and supposed to palliate the loss of the partial objects of auto-eroticism. This composition of narcissism, which is here confused with the ego, allows Green to explain narcissistic anxiety: "The representations of the ego are in fact object representations that are disguised as representations of the ego by narcissistic cathexis. This is in agreement with Freud's sentence where the ego, addressing the id, says: 'See, you can love me, I look so much like the object'. From then on, the important question of narcissistic anxiety becomes clear: phenomenologically, we are entitled to describe its manifestations;

${ }^{9}$ My translation. 
theoretically, narcissistic anxiety is anxiety of objects disguised as narcissistic objects, narcissism knowing properly to speaking only about emotions - in the order of displeasure - pain, mourning, hypochondria." (Ibid., p. 140) This register can be found in Windisch, Herta Müller's first character, but not in her second character, who represses all emotions.

Narcissism supposes, apart from the internal reproduction of the object, a desexualized cathexis. The ego, as Freud pointed out, works with 'desexualized energy'. Desexualisation is relative, as it is possible to redirect it to an object. According to Green, the energy converted by desexualisation "[...] serves to constitute the specific aspect of the cathexis of the ego: self-preservation, assurance of its limits and cohesion, firming of its consistency (in every sense of the term). etc. Above all, this narcissisation guarantees the functioning of the ego by the love he feels for himself: its faith in him, if I may say so.” (Ibid., p. 158) This type of operation allows a distance to be maintained from the drive. But in the extreme conditions of a labour camp, it is imposed from the outside. It is for this reason that Leo's libido is only used to satisfy selfpreservation needs. There are many demands that the ego must satisfy, but, from the perspective of this analysis, the essential thing would be that it maintains its cohesion, precisely thanks to the energy diverted from the object to its own benefit. Although the object makes sexual development possible, it can still destabilize the ego. According to Green "[...] the object that is originally the purpose of the satisfactions of the Id is actually for the Ego, in some ways, always a cause of imbalance - to say it all, a trauma. If it is true that the Ego aspires to unification and that this internal unification extends to unification with the object, the total union with the object forces the Ego to lose its organization. Moreover, 
when this reunification is impossible, it also disrupts the Ego when the latter does not tolerate this separation. The object-trauma (for narcissism) then leads us to consider the Ego not only as the seat of the effects of the trauma but also as the reaction against this dependence on the object, reactions which constitute an important part of the defences of the Ego, not against anxiety, but against the object whose independent variations trigger anxiety. Thus in the series: early traumatism - defence (this set constituting fixation) - latency - explosion of the neurosis - partial return of the repressed, I would like to underline the confusion between the drive (represented by the affect) and the object, for the danger comes as much from the breaking of sexuality into the Ego as from the breaking of the object." (Ibid., p. 160). A whole dialectic is underlined, in a context that does not prevent the object from being traumatic while it indirectly ensures the drive excitation which allows psychic growth. The trauma is already there, as a necessary dimension of the object relation. The trauma is also present in the two characters described. Apparently of a sexual nature in Windisch, it becomes a narcissistic wound. Of a self-preserving nature in Leo, it cancels almost all forms of sexuality, except for the interest in food which is itself at risk of being for pleasure.

Despite the difference between sexuality and narcissism, there is always a possible flow between the two types of cathexis, which can ultimately clarify the problem of narcissistic anxiety. In Green's vision, the object plays a role, but the ego remains the main actor: "If subsequently the disappointment of the object, or both objects in the oedipal configuration, forces it into narcissistic withdrawal it will find there a precarious, but protective refuge in self-idealization. And when this shelter, this self-implantation, will be threatened, it will experience 
narcissistic anxieties. Regressive anxieties, no doubt, but regression without a fundamentally destructive character of psychical reality and of external, material reality." (Ibid., p. 164) This results in the fact that narcissistic anxiety requires the ego to be fairly well constituted and separated from the object. Separation, by itself, does not destabilize too much, but the ego can feel threatened without being able to distort the internal reality or that of the outside world. There are the psychotic anxieties, in Green's vision, that modify these two realities. The ego must fight against both the drive and the object. In narcissistic anxiety the object is rather neutralized, whereas the ego takes all the weight of the conflict which caused the disappointment. Green carefully searches for the reason behind the existence of narcissistic anxiety in a rather neurotic register where the object can be sexually invested. The narcissistic image is quite coherent and the ego can also love itself. This context suits Windisch's situation, and even Leo's situation. The intervention of narcissistic anxiety allows reality to become distorted, and for the outbreak of psychosis to be blocked. The danger directly targets the ego, but is not so strong that it loses its unity.

\section{Gender difference and narcissistic anxiety}

If we go back to the literary creation of Herta Müller, she identifies more with female characters rather than male ones, hence the question of whether the anxiety that would be common in the totalitarian regime presented would have a gender specification. At least three of these novels that describe everyday life under the communist regime have female protagonists, all targeted by the secret police, as was in fact the writer herself. In The Land of Green Plums (2010) the protagonist is a young female student who forms a close-knit group with three male 
friends, met after the suicide - or the caused death? - of a campus colleague. Then they are all summoned periodically to the secret police, where they are interrogated by the same investigator, accompanied by his dog. This woman and her friends are all from German communities. The harassment of the secret police makes them very sensitive, like an animal of the heart (a direct translation of the original, German title - Herztier given to Herta Müller's novel The Land of Green Plums), but to a certain extent they manage to hold their ground quite well. There does not seem to be a way to feel specifically feminine. Eventually, the secret police pressured the group's members to emigrate, and two of the three men died at the end of the story.

In the other two novels, the situation is a little different. The protagonist of The Fox was ever the Hunter (2016), Adina, becomes a target of the political police for several apparent, but vague, reasons. Agents enter her apartment and cut off pieces of the fox fur she has in her living room. When the fox's second leg is cut, she begins to be afraid: “Adina pulls her stockings over her legs, but her legs aren't really inside the stockings. She puts on her coat, but her arms are not really in the coat." (Müller, 2016, p. 163) This is a form of depersonalization that manifests itself as a kind of distance from one's own body. In The Appointment (2011), the heroine with whom the writer identifies is guilty of a slight professional misconduct. Gradually, she shares her existential history. During her first marriage, she learns during the party that her grandparents were deported to a concentration camp by her future fatherin-law. The grandmother never came back. The heroine remembers what she experienced at the party: "When I went back into the hall, I felt I needed someone to help me to crawl out of my skin. But nobody did, so I 
wolfed something down." (Ibid., p. 176) An attack on the self-image could be invoked, which, in this passage, is worthy of a very powerful form of depersonalization. Given the paradoxical situation, to enter the family of a strong male figure of the regime that destroyed her family of origin, she still manages to overcome the moment. But this is a form of anxiety that may annihilate the person. At the same time, all these difficult moments represent forms of intrapsychic overflow, traumas. The generated anxiety seems to provoke cleavages allowing the unity of the ego to be saved. From another perspective, one can notice that female characters tend, in the totalitarian context described, to have stronger feelings than male characters and which involve the body more. The character of The Land of Green Plums, well surrounded by her male friends, does not describe the same type of feelings, as the group protection offered her a form of defence limiting the proportion of her emotions to the intrapsychic space. The question is whether this difference, illustrated in Herta Müller's prose, could be supported by psychoanalytic arguments.

\section{Between castration and annihilation}

From a clinical perspective, the register of anxiety could be delimited by castration anxiety, on the one hand, and annihilation anxiety, on the other (Clit, 2001). Castration would be the mark of neurosis, while annihilation is the mark of psychosis. It is well known that the danger of castration is particular to men, and that Freud has postulated an equivalent in women: "Its place is taken in their sex by a fear of loss of love, which is evidently a later prolongation of the infant's anxiety if it finds its mother absent." (Freud, 1933, p. 87) As this type of anxiety does not have much specificity, Green has proposed the anxiety 
of penetration as a female equivalent. The wounded self is torn "[...] between the anxiety of narcissistic castration and the anxiety of penetration of the fantasised vagina" (Green, op. cit., p. 170). The ego / narcissism in question is more masculine, and at risk of being lost in a fantasised vagina that can only be dangerous. It is not even the female side of this male character, only the dangers of penetration that add to those of castration. The threat of castration extends beyond coitus, calling into question the sexual power of man. In the same way, the anxiety of penetration would typically be a feminine danger. On the other hand, there is only one vague suggestion of genital intercourse which consists of the penetration of vagina by the penis. It is around the genital union that the typical anxieties of either sexes, or genders, are organized: the anxiety of male castration disables the male member, the anxiety of female penetration makes penile reception dangerous. For Green, these two kinds of anxiety have equivalents in the non-neurotic register, namely the narcissistic one. At this level the subject is taken "[...] between the anxiety of separation which signifies the loss of the object and the anxiety of intrusion, the danger of invasion by him, where the desire to merge will be synonymous with a vampirisation by the object" (Ibid., p. 160). The separation would be the consequence of castration, the intrusion that of penetration. So, the effect of the threat felt in the sexual register would have much stronger implications on a narcissistic level. And despite these two versions, masculine and feminine, narcissistic anxiety, intrusion and / or separation, seems to have the same devastating effect on self-image.

Other differences between the two genders could be pointed out: there would be more continuity between intrusion and penetration, than 
between separation and castration. Intrusion and separation involve total objects, while penetration and castration emphasize a relationship between a partial object (the sexual organ) and a total object (the body). Intrusion and separation are all about the subject. Penetration is a limited intrusion of limited interiority (the vagina). In the same way, castration is a compartmentalized separation, with a partial object (the penis), highly valued. The organ that is the penis, replaces the object, while between intrusion and penetration there is no similar symbolic relationship. The common element in both genders at the level of neurotic anxiety is that the external danger is circumscribed to a part of the body, which would ensure the survival of the whole. But this derivation is less effective in women. Thus, we can better understand that the traumatic feelings of female characters are stronger and involve the body, because their capacity to contain within the psychic sphere would be more difficult to achieve. The feminine side, intrusion - penetration would have both a concrete appearance, in the care given to any baby, and a precedence in relation to its male corollary. J. André has launched the hypothesis of a common feminine origin of sexuality in both sexes, starting from the initial passivity of the baby: "The intrusion into the psychosoma of the child willingly borrows orificial routes (mouth, anus), for both sexes. This intrusion somehow finds a differed confirmation in the female genital representation (or in the anal identification in males)." ${ }^{10}$ (André, 129). An important memory of this initial position in man would not remain. He probably projects, to a great extent, his initial status of penetrated body onto the woman and her vagina. Moreover, the quote emphasizes that the intrusion of the orifices through the care provided

\footnotetext{
${ }^{10}$ My translation.
} 
acquires a sexual meaning only later. Besides, the difficulty of the penetration suggests intrusion.

In males, separation may be a more acceptable danger than intrusion. Separation also has a feminine impact, going beyond the masculine side of the woman. It can be experienced with more displeasure, suggesting the intrusion. In any case, even in this distinction between male separation anxiety and female intrusion anxiety, there is a genital imprint, a meaning derived from the genital function of the penis and of the vagina. The existence of the relationship between the specific anxieties of the two genres refers to a relationship between narcissistic and sexual (neurotic) anxiety. However, Green's distinction between separation anxiety and intrusion anxiety seems more general at the level of narcissism than the castration anxiety - anxiety of penetration couple is in the sexual register. In any case, narcissism would be caught between separation and intrusion. This distinction would make it possible to understand the situation of the narcissistic women mentioned in Freud's text from 1914. Apparently they cathect their libido onto themselves, and especially on their body. In fact, the presence of intrusion anxiety shows that the register of the interior of the body is much more important than in males. In the latter, the most valuable organ, the penis, is located outside the body. Its loss would not put his survival at risk, as a sexual threat would to women.

The larger investment of the body in women would isolate a female type of narcissism. The narcissistic women described by Freud form a category that has the merit of embodying a tendency less explicit among other representatives of their gender. Illustrated by Herta Müller's 
female characters, this feminine narcissism is easier to describe in the particular social context of her novels, which would endanger the existence of any individual. Thus, the female body shows its vulnerability as a whole, and requires a cathexis that cannot always be offset by masculine identifications. As the body and especially its image is one of the sources of narcissism, it would be justified to postulate the existence of a female narcissism, one to be distinguished from a male equivalent.

\section{Conclusions}

Following Freud's suggestion, masculine identification in women was analysed in a writer's case. It seems that they are not limiting the existence of feminine identifications. But another interesting difference was found between masculine and feminine characters in Herta Muller's novels: the body involvement in experiencing anxiety in women. It is especially through the presence of anxiety that narcissism could have a gender, or present gender differences. Anxiety is the internal state which could lead, in special conditions, to the disorganization of the psychic structures. Concerning narcissism, in women its disorganization danger should come mainly from inside of the body, whilst in men it should be especially linked to castration, an external danger.

These remarks were possible by using literary references, depicting a quite special society, ruled in a totalitarian way. It will be possible to consider they would need a confirmation in other social conditions, but it is also possible to argue that special conditions are only revealing forms of psychic functioning not so evident in more average conditions. Anyhow, a clinical confirmation of this point of view will render it more reliable. 


\section{REFERENCES}

ANDRE, J. (1995). Aux origines féminines de la sexualité [At the Feminine Origins of Sexuality]. PUF, Paris, p. 164.

CLIT, R. (2001). Cadre totalitaire et fonctionnement narcissique [Totalitarian Framework and Narcissistic Functioning]. L'Harmattan, Paris, p. 311.

CLIT, R. (2018). Du trauma à l'angoisse. Un point de vue sur la créationlittéraire de Herta Müller [From Trauma to Writing. An Outlook on Herta Muller's Literary Creation]. L’Harmattan, Paris, p. 226.

FREUD, S. (1914). On narcissism: An Introduction, SE XIV. Hogarth Press, London, 1957, pp. 73-102.

FREUD, S. (1933[1932]). New Introductory Lectures on PsychoAnalysis. SE XXII. Hogarth Press, London, 1964, pp. 3-182.

GREEN, A. (1983). Narcissisme de vie, narcissisme de mort [Life Narcissism, Death Narcissism]. Minuit, Paris, p. 280.

MULLER, H. (1989). The Passport. Serpent's Tail, London, p. 93 p. MULLER, H. (1999). Nadirs. University of Nebraska Press, Lincoln, p. 119. MULLER, H. (2010). The Land of Green Plums, Picador, New York, p. 258. MULLER, H. (2011). The Appointment. Portobello Books, London, p. 214. MULLER, H. (2013). The Hunger Angel. Portobello Books, London, p. 290. MULLER, H. (2016). The Fox was Ever the Hunter. Portobello Books, London, p. 237. 